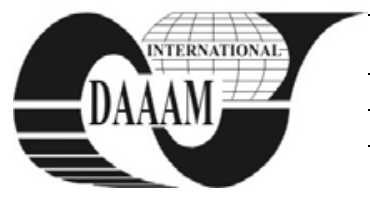

\title{
PRISMATIC MILLING SIMULATION PROCESS AND CNC PROGRAMMING IN THE CAD/CAM SYSTEM CATIA V5R20
}

\author{
MAJERIK, J[ozef] \& JAMBOR, J[aroslav]
}

\begin{abstract}
The aim of this paper was to clarify the simulation process of selected components in the interface of CAD/CAM system CATIA. This process is important to enter the process of manufacturing of various precision engineering components of complex shape designed for the needs of automotive and aerospace industries. Using the highest level of programming through graphical engineering system is designed for creating ISO programs using CNC machines. These processes are generally described in the introductory chapter. The next two chapters systematically deal about the process of model creation with subsequent determination of machining strategy, tool selection and cutting parameters. Chapter four and conclusions show the entire production process-simulation on a practical example of production parts in practical terms.

Key words: prismatic milling, simulation process, machining strategy, CNC programming, CAD, CAM systems
\end{abstract}

\section{INTRODUCTION}

CATIA V5 is one of the higher CAD/CAM systems, because in addition to modeling and offers technical documentation and production assembly kits, assemblies and design areas of thin metal sheets, different strength analysis, as well as simulate turning, milling moulds, drilling etc. 3D model created from CAD part of CATIA is then inserted to a process of simulation, where is generated NC code for the various control systems, CNC machining centers (Majerik, et al., 2010).

In our practical demonstration of the contribution referred to the production of parts has been pursued in the research linking theory and practice in the subject of Operations Management in the VSM-The School of Management in Trencin, Slovakia.

\section{CREATION OF 3D MODEL \& ROUGH STOCK}

The mere creation of models with components using CATIA V5 is implemented using the main Start menu, where they are located SKETCHER subsections, which is 2D creation of sketches and shapes, serving as a basis for later create 3D models in other parts of the product such as CATIA V5 DESIGN PART, Generative SHAPE DESIGN, SHEET METAL DESIGN, Wireframe and Surface Design, WELD DESIGN, etc. The basics of using CATIA V5, is the proper use and therefore the transition from 2D plane in the first dimensional space, but not least the construction site. In order to establish a complex and multiple mounting kit, create a flawless technical drawings, it is important to know appropriate to set up different models of machine parts, which form the basis for further work and subsequent CAD and CAM systems team. The advantage of the underlying modeling and creating sketches lies in simplifying the control itself, ie used all the features and icons are mostly single-level, resulting in a much better insight into the work itself, unlike some other CAD systems. After creating 2D sketches through the "Exit Workbench" get into 3D environments such as PART DESIGN, SHAPE DESIGN, etc.. In fact the 3D environment, then use the appropriate functions, depending on the type and the shape of the future model components to create the final PART or part of the product, if you worked for in subsection ASSEMBLY DESIGN. CATIA V5R advantage is its transparency, icons are placed directly on the sides of the active desktop, or you can activate them via the main menu ViewToolbars. This structure of the system is necessary in view of the scope and job opportunities CATIA. Moreover, it is possible to work in the CATIA documentation created in older CAD systems, such as. DWG from AutoCAD, as in subsection called INTERACTIVE Drafting. Modeling procedure itself is clearly stated in the so-called working application tree, which is always on the left side of the active desktop.

\section{CAM PROCESS AND MACHINING STRATEGY}

Individual acts necessary for the design of machining on CNC machining centers in the CAD/CAM system CATIA V5 R20 Machining modul are as follows:

- Determine appropriate and Geometric BODY SET for parts and semi-on working tree. Create a 3D model parts in CATIA V5.

- Create a blank with those allowances which will be model.

- Go to the machine mode of CAD/CAM system CATIA V5.

- Parameter setting tool, which will perform roughing model.

- Define the machining operations, which are determined semi-alone model, the machining allowance, tolerance, sliding, speed and infeed machine tool path.

- Set parameters of other instruments which will perform profiling.

- Define the machining operations, which also set aside all the parameters (Dillinger, et al., 2007).

- Running simulations of machining, simulation output control machining (can see on Fig. 1, 2).

- NC code in the form of ISO, as appropriate CNC machine and control system (Jambor \& Majerik, 2009).

After creating a technological process of production, the choice of an appropriate strategy roughing and finishing the functional areas of the drawing tool milling tools to select suitable material, geometry and cutting plate holder. Then determine the optimum cutting parameters for each roughing and finishing hard milling (feed, cutting speed). Model created with the tool, along with intermediate put into the environment module of CATIA V5 NC Manufacturing in the work of the tree PRODUCT LIST. Creation of the production process is at the top of the tree under the name PROCESS LIST. Process through the menu is listed in NC Manufacturing module design type CNC machine tool.

Then we determine the zero point of the workpiece coordinate system of the machine, the type of post-processors to generate NC code for FANUC (Jandecka, et al., 2007).

Through Auxiliarry operations generate oprimal shape and material, tool holders, cutting plates and determine the strategy (Fig.3) of whole process of production using Machining milling operations. Using the tool path replay and simulate the process 
of routing module Generating NC code then generates the NC program in ISO format ( $\mathrm{G}$ and $\mathrm{M}$ codes), using a memory card, transferred to a control system for CNC machine tool.

\section{CNC PROGRAMMING IN CATIA \& RESULTS}

NC code in CATIA V5R20 is implemented through function Generative NC code. When activated, this icon to formation of the NC program from the active machining process, which was designed in the previous steps. Before the act of generating NC code necessary to determine the correct data on the method of machining, tool and defining its holder. The generated NC code can be further edited on a computer or directly to the CNC machining center, the second option is not desirable in terms of production efficiency. A necessary early step is to delete the generated NC code, therefore, since these data are set in the CNC machining centers and the abolition of numbering lines.

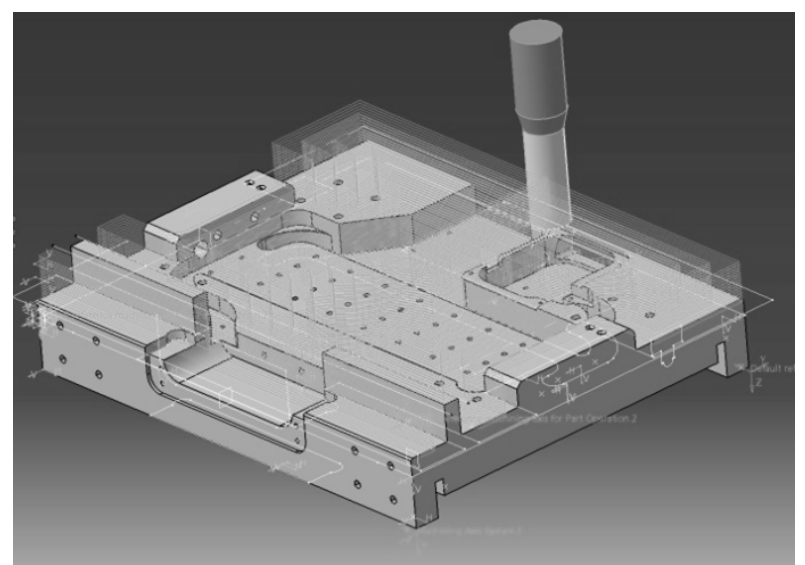

Fig. 1. Prismatic milling process on selected component

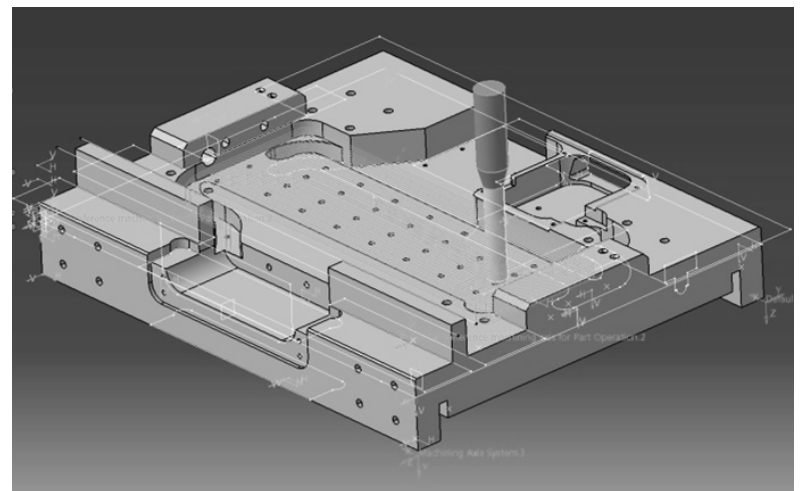

Fig. 2. Simulation process of prismatic milling process simulation in CAM part of CATIA V5R20

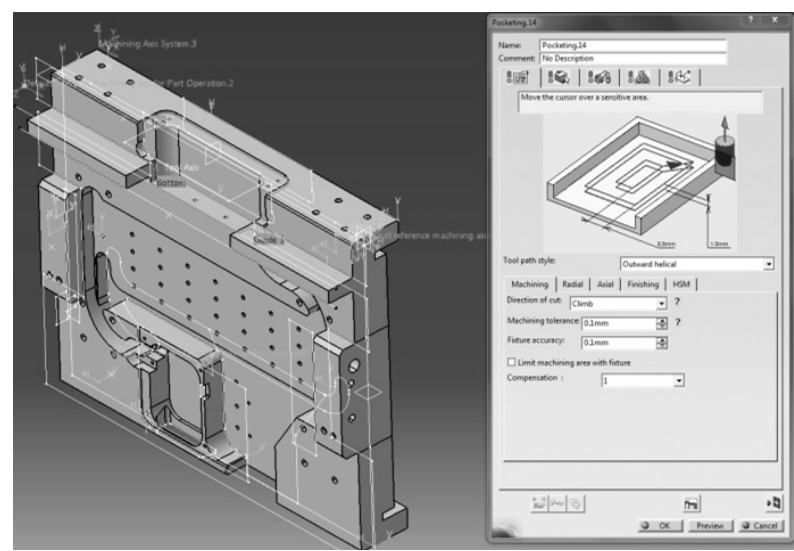

Fig. 3. Strategy of prismatic milling process, and dialog panel for strategy of milling process settings
It is important to change the file to NC code program without an extension, was known to process CNC machining center. The last stage is to upload NC code for portable media and injected into a CNC machining center, which operate codes directly from portable media due to lack of internal memory machining center (Globan, 2009).

Prismatic milling model components were carried out on a vertical machining center with the SH610 STORM system FANUC Series 0i-MC (Majerik \& Danisova, 2009).

Machine parameters: Working feed $=1 \div 10000 \mathrm{~mm} / \mathrm{min}$ Workbench 700x450 mm, Table load max $300 \mathrm{~kg}$ Max. spindle speed $10000 \mathrm{rev} / \mathrm{min}$, spindle taper SK40 Workspace: X-axis (610mm), Y-axis(460mm), Z-axis(480 mm) Shifts: Rapid $X / Y=36 \mathrm{~m} / \mathrm{min}$ rapid traverse $Z=24 \mathrm{~m} / \mathrm{min}$ Roughing: $\mathrm{n}=1490 \mathrm{~min}, \mathrm{f}=1700 \mathrm{~mm} / \mathrm{min}, \mathrm{a}_{\mathrm{p}}=0.8 \mathrm{~mm}$. Finishing: $\mathrm{n}=2900 \mathrm{~min}, \mathrm{f}=2300 \mathrm{~mm} / \mathrm{min}, \mathrm{a}_{\mathrm{p}}=0.15 \mathrm{~mm}$. Workpiece material: tool steel TOOLOX 44 with 45 HRC

After clamping the stock was vice settings planes and other corrections that are needed to start machining. Milling model was used cylindrical roughing cutter with a diameter of $32 \mathrm{~mm}$ carbide insert, stem diameter of $32 \mathrm{~mm}$ radius of curvature of 2 $\mathrm{mm}$. Profiling model has been implemented cylindrical cutter with a diameter of $16 \mathrm{~mm}, 16 \mathrm{~mm}$ shank diameter of $2 \mathrm{~mm}$ radius. The additional material from the milled grooves was used spherical cutter with a diameter of $6 \mathrm{~mm}, 6 \mathrm{~mm}$ diameter stem. Milling was carried out without cooling the emulsion as a medium for removing particles was used compressed air.

\section{CONCLUSION}

The advantage of dealing with the issue of creating $\mathrm{NC}$ code in the CAD/CAM system CATIA model for machining on a vertical milling machine tool system is that the creation of the NC program for a relatively short period of time due to the complexity of the shape components utilized milling. Facility these systems is sufficiently rapid generation of NC code and its easy adaptation to a suitable form for the CNC machining center. Using the systems with CNC machining center in practice reduces the risk of errors arising during operation models. All this was practically demonstrated in the research organization VSM-The School of Management in Trencin from Slovakia in cooperation with MASH Integration Co. Trencin.

\section{REFERENCES}

Dillinger, J. et al. (2007). Modern Engineering for school and praxis, Europa Sobotales, ISBN 978-80-86706-19-1, Praha,

Globan, P. (2009). Analysis of Cutting Conditions at Milling Process of the Selected Components, Available from: http://fst.tnuni.sk, Accessed: 12.6.2009

Jambor, J \& Majerik, J. (2009). Hard Die\&Mould Milling Process with CAD/CAM system CATIA V5R18 Support, Annals of DAAAM for 2009 \& Proceedings of the 20th International DAAAM Symposium, 25-28th November 2009, Austria Center Vienna, ISSN 1726-9679, ISBN 9783-901509-70-4, Katalinic, B.(Ed.), pp. 1465-1466, Vienna

Jandecka, K. et al. (2007). Postprocessors and Programming of CNC Machine Tools, FVTM UJEP, ISBN 978-80-7044870-0, Usti nad Labem, Czech republic

Majerik, J. et al. (2010). Automation of the Production Process for Metallic Flexible Diaphragm with CAD/CAM system Catia V5R19 Support, Annals of DAAAM for 2010 \& Proceedings of the 21st International DAAAM Symposium, 20-23rd October 2010, Zadar, Croatia, ISSN 1726-9679, ISBN 978-3-901509-73-5, Katalinic, B.(Ed.), pp. 06230624, Vienna, Austria

Majerik, J. \& Danisova, N. (2009). Automation \& Simulation of Milling Process with CAD/CAM system CATIA V5R19 support. AI Magazine - Automotive Journal, Vol.2, No.4, (September 2009) page numbers (20-22), ISSN 1337-7612 